\title{
Knowledge, attitudes and behaviour regarding nutrition and dietary intake of seventh-grade students in rural areas of Mi Yun County, Beijing, China
}

\author{
Dongxu Wang $\cdot$ Yuhui Shi $\cdot$ Chun Chang \\ Donald Stewart $\cdot$ Ying Ji $\cdot$ Yanling Wang • \\ Neil Harris
}

Received: 20 September 2013/ Accepted: 25 November 2013/Published online: 18 December 2013

(C) The Japanese Society for Hygiene 2013

\begin{abstract}
Objectives To investigate the knowledge, attitudes and behaviour of seventh-grade students regarding nutrition and dietary intake, to collect data that would facilitate the design and implementation of interventions aimed at promoting good nutrition in adolescents via the school and to contribute to the improvement of adolescents' health in rural regions.

Methods This was a descriptive, cross-sectional study in which a 27-item, self-administered, structured questionnaire, designed in Chinese, was administered to seventhgrade students attending one of three rural middle schools, chosen randomly from 15 middle schools, in Mi Yun County, Beijing.

Results In terms of nutrition knowledge, $84.5 \%$ of respondents had scores of between 3 and 7. Based on our analysis of the completed questionnaires, during the 7 days preceding completion of the questionnaire $43.6 \%$ of respondents had eaten fresh fruit at least once per day, $71.3 \%$ had eaten vegetables at least once per day, $22.3 \%$ had consumed at least one glass of milk (or soy milk or yogurt) each day and $68.6 \%$ had eaten breakfast every day. In total, $95.2 \%$ of respondents thought nutrition was very important or important to their health, and $94.2 \%$ thought it was very important or important to develop healthy dietary habits. Of the respondents, $52.7 \%$ thought
\end{abstract}

D. Wang $(\bowtie) \cdot$ D. Stewart $\cdot$ N. Harris

School of Public Health, Griffith University, Room 4.08/S07, South Bank Campus, PO Box 3370, South Brisbane, QLD 4101, Australia

e-mail: p06240401@163.com

Y. Shi · C. Chang · Y. Ji · Y. Wang

School of Public Health, Peking University, Beijing 100191,

People's Republic of China good food quality was the most important aspect of nutrition and dietary intake and $62.2 \%$ thought food safety was the most important aspect.

Conclusions Based on the results of our survey we suggest their should be continuous efforts to teach adolescents in rural areas of China about various aspects of good nutrition, to encourage diversity in their choice of breakfasts, to guarantee food safety and to improve food quality.

Keywords Nutrition - Dietary intake $\cdot$ Students ·

Rural areas · Beijing

\section{Introduction}

The links between nutrition and health are well known, with good nutrition accepted as one of the primary determinants of optimal growth, good health and well-being [1, 2]. Accordingly, an unhealthy diet has been identified as a major risk factor for the global increase in chronic noncommunicable diseases, such as coronary artery disease, cardiovascular disease, cancer, diabetes and obesity. A large proportion of these diseases can be avoided as they are either initiated or accelerated by unhealthy nutrition in addition to other etiologies [3-5].

In recent years, there has been a growing worldwide concern about the dietary and nutritional needs of adolescents [6-8]. Studies indicate that good nutrition is especially important during adolescence, which is a period of biological and social change. These are crucial years for normal physical and mental development, and the diet and eating behaviours that develop during these years tend to persist throughout life $[9,10]$. During adolescence, body size and composition, bodily functions and physical abilities change rapidly, and under-nutrition can slow height 
and weight growth and may delay puberty [11-14]. In addition, healthful eating habits in young people not only help to prevent under-nutrition, growth retardation and acute nutritional problems, but also lower the risk of developing chronic non-communicable diseases [15, 16]. Moreover, good nutrition and health can enhance students' educational performance and learning [17].

Nutrition-related health problems among the youth are apparent in developing countries where, paradoxically, both over- and under-nutrition can coexist. China is a newly industrializing country that is currently experiencing a severe challenge in the area of health and nutrition [18, 19]. Studies have shown that nutritional deficiencies and over-nutrition are significant in many parts of China and that the problem is growing [19, 20]. A national survey on diet and nutrition in 1992 revealed that while the energy intake of young people aged 2-18 years reached $97 \%$ of the recommended daily allowance (RDA), nutrient intake was unbalanced [21]. Another survey conducted in eight Chinese cities in 1996 revealed an increase in obesity from $3.4 \%$ in 1985 to $7.2 \%$ among students aged 7-18 years [22]. Recent statistics released by the Chinese Capital Institute of Pediatrics in 2011 show that among youth aged 0-18 years in Beijing, $20 \%$ are overweight or obese and that the obesity rate has increased by five- to sevenfold over the last 20 years [23]. What is also noticeable is that adolescents in rural areas of China, which are relatively more affected by poor living conditions and low family income than those in urban areas, have a low level of health awareness and health knowledge, as well as unhealthy eating behaviours [24, 25]. Moreover, youth in rural areas have a poorer nutrition and dietary intake pattern than their counterparts in urban areas of China [26].

China has been in a state of rapid social, nutrition and health transition in recent decades [27], and owing to lower prices and increasing affluence; food supply and diversity have increased in both urban and rural areas in association with economic growth $[28,29]$. At the same time there has been an increasing concern about the quality of the food available and the general issue of food safety. In 2003, the state food and drug administration of China (SFDA) was founded to consolidate food and drug regulations, and in 2009, the food safety law of the People's Republic of China came into effect. At present, there are 1,070 national food standards and 1,164 industry-specific standards in China, but despite these efforts the efficacy of these regulations in reducing the incidence of food safety episodes remains largely an exercise rooted in faith, as expressed by the Chinese vice premier and head of the food safety commission, Li Keqiang, on Feb 8, 2012 "China still faces a grave situation in ensuring its food safety" [30-33].

To date, however, little information derived from integrated studies is available on the knowledge, attitudes and behaviours of adolescents from rural areas of China regarding nutrition and dietary intake. Large rural regions surround the Chinese capital of Beijing, and these are included in the Beijing administrative entity. Mi Yun County, northeast of Beijing, is one of these rural areas. In July 2012, we conducted a survey in middle schools located in Mi Yun County to obtain more detailed information about the knowledge, attitudes and behaviours of adolescents in rural areas of Beijing, China in relation to nutrition and dietary intake. The rationale for this study was to improve our knowledge of rural adolescents regarding their own knowledge, attitudes and behaviours relating to dietary intake and nutrition, to collect data that would facilitate the design and implementation of interventions aimed at promoting good nutrition in adolescents via the school and, consequently, to contribute to the improvement of adolescents' health in rural regions of China.

\section{Materials and methods}

This was a descriptive, cross-sectional study that was conducted from June to July 2012. The project was approved by the Human Research Ethics Committee of Griffith University (reference no: PBH/14/12/HREC) and by Peking University Institutional Review Board (ethics review approval no: IRB00001052-12024).

\section{Research questionnaire}

The instrument for the study was a 27-item, self-administered, structured questionnaire that had been designed in Chinese. The questionnaire was divided into four main sections and used to assess the respondent's knowledge, attitudes and behaviours in relation to nutrition and dietary intake. Section A (personal information) and Section C (food consumption frequency) were derived from the questionnaire used in the 2004 China Adolescent Behavioural Risk Factor survey, designed by the Institute of Child and Adolescent Health, Peking University. The questionnaire used in 2004 had been pre-tested on a small scale before it was widely used in China. Section B (nutrition knowledge) was derived from two English questionnaires and was translated into Chinese; one questionnaire was accepted as reliable (mean Cronbach's alpha 0.73 [34]), and the internal reliability of the second questionnaire (Cronbach's alpha) was 0.57 and the test-retest reliability 0.80 [35]. Section D (nutrition attitudes) was drafted as an original in Chinese. Thus, Sections $A$ and $C$ had been used in China prior to our study, and Sections B and D had not. Section A contained questions on personal data, Section B investigated students' knowledge of nutrition (10 questions, each with 5 response categories structured in different 
ways). The 'true' response of each question received a score of 1 , with 0 for the other response; and the total score of this section was 10 . Section $\mathrm{C}$ examined the frequency at which students consumed food, with the aim of investigating weekly consumption patterns of fruit, vegetable, milk and breakfast. Section D investigated students' nutrition attitudes, including attitudes towards food expiry dates, the importance of nutrition and developing healthy dietary habits. Each questionnaire took about $20 \mathrm{~min}$ to complete. Standardization of the questionnaire was also ensured by carrying out a pilot study on 70 students in a school randomly selected from the rural areas of Mi Yun County. Following the pilot study, minor adjustments were made to the questionnaire, such as deleting unnecessary options of certain questions and simplifying language, prior to the commencement of the study. The reliability of the questionnaire was investigated using Cronbach's alpha, which indicated a score of 0.890 .

\section{Study population and data collection}

Three schools were randomly selected from 15 middle schools in Mi Yun County to participate in this survey; we refer to these schools as School A, School B and School C hereafter for convenience. At total of 1,736 second-year students attended these three schools. Taking into account the need for the sample to be representative and limited funding, we determined that $10 \%$ of these students should participate in the survey; this would be 174 students, plus $10 \%$ extra for non-responders, coming to a total of 191 students. Ultimately, we decided to survey 195 students, and randomly selected 65 second-year students from each of the three middle schools to complete the questionnaire. The questionnaire was self-administered to the student sample. Respondents were provided with full information about the study, and informed written consent was obtained from each subject and from their parents/guardians. The investigator was a Mandarin-speaking researcher who had received prior training in public health nutrition.

\section{Statistical analysis}

Using Epidata 3.02 software, data were coded and entered onto a computer, and then logical error detection and verification were carried out to exclude missing data and abnormal values.

Analysis was performed using SPSS 20.0 (SPSS Inc., Chicago, IL) software. Statistical analysis was done using the mean and standard deviation (SD) to summarize each student's age, and score on nutrition knowledge. Frequency and proportion were calculated to describe gender, nationality, awareness rate of nutrition knowledge, dietary intake and attitudes relating to nutrition. Measure of association was carried out using the Chi-square test and $t$ test as appropriate; a $p$ value $\leq 0.05$ was considered to be significant . If $N \geq 40$ but $1 \leq t<5$, the corrector formula was used to do the Chi-square test. The Chi-square test for relatedness was also used to examine the correlation between respondents' nutrition knowledge awareness and relevant eating behaviours. The 'true' response for each knowledge question received a score of 1 , with 0 for the other response. The 'true' response for the questions on healthy eating behaviour, such as eating breakfast every day, consuming vegetables and fruits at least once per day and drinking at least one glass of milk (or soy milk or yogurt) per day, received a score of 1 , with 0 for unhealthy behaviours.

\section{Results}

Study population characteristics

A total of 195 students were invited to complete the questionnaire during school class time. In all, 188 students completed the questionnaires, which is a response rate of $96.4 \%$. Of the respondents, 91 were male $(48.4 \%)$ and 97 were female $(51.6 \%) ; 62,65$ and 61 were from School A, School B and School C, respectively. The mean age of the respondents was $12.80 \pm 0.45$ (range 12-14) years, and $87.8 \%$ were of Han nationality. There was no statistically significant difference in student's age, gender and nationality across the three schools

\section{Nutrition knowledge}

In terms of the ten items on nutrition knowledge, the knowledge area with the highest awareness rate $(87.8 \%)$ was that vegetables and fruits are rich in vitamin $\mathrm{C}$, followed by the knowledge that breakfast is the most important meal $(68.8 \%)$, that dietary products and beans are rich in calcium $(68.8 \%)$ and that inadequate preservation is most common factor responsible for food poisoning $(67.0 \%)$. The question with the lowest awareness rate related to the main function of vegetables: only $16.0 \%$ of respondents knew that the main function of vegetables is to protect against infections. The awareness rates of the symptoms of food poisoning, the minimum number of glasses of water $(250 \mathrm{ml} / \mathrm{glass})$ people should drink each day, the foods that are richer in protein and the main function of dietary products also did not score well, all being $<50 \%$. With the exception of students' awareness of vegetables and fruits being rich in vitamin $\mathrm{C}$, there was no statistically significant difference in students' awareness rate of nutrition knowledge by gender (Table 1).

In terms of nutrition knowledge, two respondents $(1.1 \%)$ answered all questions incorrectly, and no respondents 
Table 1 Respondents' awareness of nutrition knowledge by gender

\begin{tabular}{|c|c|c|c|c|c|c|c|}
\hline \multirow[t]{2}{*}{ Knowledge of nutrition } & \multicolumn{2}{|c|}{$\begin{array}{l}\text { Male } \\
(n=91)\end{array}$} & \multicolumn{2}{|c|}{$\begin{array}{l}\text { Female } \\
(n=97)\end{array}$} & \multicolumn{2}{|c|}{$\begin{array}{l}\text { Total } \\
(n=188)\end{array}$} & \multirow[t]{2}{*}{$p$} \\
\hline & $N$ & $\%$ & $N$ & $\%$ & $N$ & $\%$ & \\
\hline Grain and cereals are the main energy source & 52 & 57.1 & 52 & 53.6 & 104 & 55.3 & 0.626 \\
\hline Breakfast is the most important meal & 60 & 65.9 & 69 & 71.1 & 129 & 68.6 & 0.443 \\
\hline People should drink at least 6 glasses of water ( $250 \mathrm{ml} / \mathrm{glass})$ each day & 23 & 25.3 & 27 & 27.8 & 50 & 26.6 & 0.691 \\
\hline The main function of dietary products is to build strong teeth and bones & 42 & 46.2 & 45 & 46.4 & 87 & 46.3 & 0.974 \\
\hline The main function of vegetables is to protect against infections & 13 & 14.3 & 17 & 17.5 & 30 & 16.0 & 0.544 \\
\hline Dietary products and beans are rich sources of calcium & 61 & 67.0 & 68 & 70.1 & 129 & 68.6 & 0.650 \\
\hline Vegetables and fruits are rich sources of vitamin $\mathrm{C}$ & 75 & 82.4 & 90 & 92.8 & 165 & 87.8 & $0.030 *$ \\
\hline Meat is richer in protein & 27 & 29.7 & 23 & 23.7 & 50 & 26.6 & 0.355 \\
\hline The symptoms of food poisoning depend on the types of causative germ & 18 & 19.8 & 17 & 17.5 & 35 & 18.6 & 0.691 \\
\hline Inadequate preservation is the most common factor responsible for food poisoning & 62 & 68.1 & 64 & 66.0 & 126 & 67.0 & 0.754 \\
\hline
\end{tabular}

$* p$ value $<0.05$

Table 2 Respondents' nutrition knowledge score by gender

\begin{tabular}{|c|c|c|c|c|c|c|c|}
\hline \multirow[t]{2}{*}{ Score } & \multicolumn{2}{|c|}{ Male $(n=91)$} & \multicolumn{2}{|c|}{ Female $(n=97)$} & \multicolumn{2}{|c|}{ Total $(n=188)$} & \multirow[t]{2}{*}{$p$} \\
\hline & $N$ & $\%$ & $N$ & $\%$ & $N$ & $\%$ & \\
\hline 0 & 1 & 1.1 & 1 & 1.0 & 2 & 1.1 & 0.997 \\
\hline 1 & 1 & 1.1 & 1 & 1.0 & 2 & 1.1 & \\
\hline 2 & 6 & 6.6 & 6 & 6.2 & 12 & 6.4 & \\
\hline 3 & 11 & 12.1 & 12 & 12.4 & 23 & 12.2 & \\
\hline 4 & 22 & 24.2 & 20 & 20.6 & 42 & 22.3 & \\
\hline 5 & 23 & 25.3 & 24 & 24.7 & 47 & 25.0 & \\
\hline 6 & 13 & 14.3 & 15 & 15.5 & 28 & 14.9 & \\
\hline 7 & 7 & 7.7 & 12 & 12.4 & 19 & 10.1 & \\
\hline 8 & 6 & 6.6 & 5 & 5.2 & 11 & 5.9 & \\
\hline 9 & 1 & 1.1 & 1 & 1.0 & 2 & 1.1 & \\
\hline Total & 91 & 100.0 & 97 & 100.0 & 188 & 100.0 & \\
\hline
\end{tabular}

answered all questions correctly (score of 10). The majority of respondents $(84.5 \%$ ) had a score of between 3 and 7 . The difference in the knowledge score between male and females was not statistically significant (Table 2).

Food consumption frequency

In terms of dietary intake over the 7 days preceding completion of the questionnaire, only $43.6 \%$ of respondents indicated that they had eaten fresh fruit at least once per day, $71.3 \%$ indicated that they had eaten vegetables at least once per day, and 7.4 and $1.6 \%$ indicated that they had not eaten fresh fruits and vegetables, respectively. As for drinking milk, only $22.3 \%$ respondents indicated that they had consumed at least one glass of milk (or soy milk, or yogurt) each day; this percentage was almost the same as that of the respondents $(21.3 \%)$ who did not drink milk (or soy milk or yogurt) over the last week at all. Of all respondents, $68.6 \%$ had eaten breakfast every day over the previous week, and $4.3 \%$ had not eaten breakfast at all. With respect to type of food for breakfast, the main food was grain or cereal, followed by soy milk, bean curd jelly, egg, milk and yogurt. Very few students ate meat, vegetables and/or fruit for breakfast, and boys ate more meat than girls, while girls ate more grain or cereal than boys. Overall, there was no statistically significant difference in the respondents' dietary intake over the past 7 days across the three schools by gender (Table 3 ).

Attitudes towards nutrition

The majority of respondents thought nutrition was very important or important to their health $(95.2 \%)$ and that it was very important or important to develop healthy dietary habits $(94.2 \%)$. When asked what was the most important aspect they considered when buying food, most students thought good quality was most important $(52.7 \%)$, followed by the purchase of food providing balanced nutrition $(35.1 \%)$; in contrast, the brand and packaging were not so important. Of all respondents, $62.2 \%$ wanted to know about the safety of the food, and $81.9 \%$ of them would throw away food that was older than the expiry date. There was no statistically significant difference in respondents' attitudes towards nutrition by gender (Table 4).

Correlation of nutrition knowledge awareness and healthy eating behaviours

The Chi-square test for relatedness revealed that the respondents' nutrition knowledge was not significantly correlated with relevant eating behaviours in general-with one exception: students' awareness that vegetables and fruits are rich in vitamin $\mathrm{C}$ was correlated to their behaviour of 
Table 3 Respondents' food consumption frequency during the 7 days preceding completion of the questionnaire by gender

\begin{tabular}{|c|c|c|c|c|c|c|c|}
\hline \multirow[t]{2}{*}{ Dietary intake during the past 7 days } & \multicolumn{2}{|c|}{ Male $(n=91)$} & \multicolumn{2}{|c|}{ Female $(n=97)$} & \multicolumn{2}{|c|}{ Total $(n=188)$} & \multirow[t]{2}{*}{$p$} \\
\hline & $N$ & $\%$ & $N$ & $\%$ & $N$ & $\%$ & \\
\hline \multicolumn{8}{|l|}{ How many times did you eat fresh fruit? } \\
\hline Never & 8 & 8.8 & 6 & 6.2 & 14 & 7.4 & \multirow[t]{3}{*}{0.799} \\
\hline $1-6$ times per week & 47 & 51.6 & 45 & 46.4 & 92 & 48.9 & \\
\hline At least 1 time per day & 36 & 39.6 & 46 & 47.2 & 82 & 43.6 & \\
\hline \multicolumn{8}{|l|}{ How many times did you eat vegetables? } \\
\hline Never & 2 & 2.2 & 1 & 1.0 & 3 & 1.6 & \multirow[t]{3}{*}{0.601} \\
\hline 1 time per week & 28 & 30.8 & 23 & 23.7 & 51 & 27.1 & \\
\hline At least 1 time per day & 61 & 67.0 & 73 & 75.3 & 134 & 71.3 & \\
\hline \multicolumn{8}{|c|}{ How many days did you consume at least one glass of milk (or soy milk or yogurt)? } \\
\hline Never & 18 & 19.8 & 22 & 22.7 & 40 & 21.3 & \multirow[t]{3}{*}{0.535} \\
\hline $1-6$ & 50 & 54.9 & 56 & 57.7 & 106 & 53.2 & \\
\hline 7 & 23 & 25.3 & 19 & 19.6 & 42 & 22.3 & \\
\hline \multicolumn{8}{|l|}{ How many days did you eat breakfast? } \\
\hline Never & 3 & 3.3 & 5 & 5.1 & 8 & 4.3 & \multirow[t]{3}{*}{0.775} \\
\hline $1-6$ & 22 & 24.2 & 23 & 23.7 & 45 & 23.9 & \\
\hline 7 & 60 & 65.9 & 69 & 71.1 & 129 & 68.6 & \\
\hline \multicolumn{8}{|c|}{ What kinds of food are normally included in your breakfast? } \\
\hline Milk or yogurt & 23 & 25.3 & 24 & 24.7 & 47 & 25.0 & 0.933 \\
\hline Eggs & 26 & 28.6 & 25 & 25.8 & 51 & 27.1 & 0.666 \\
\hline Soy milk or bean curd jelly & 40 & 44.0 & 37 & 38.1 & 77 & 41.0 & 0.418 \\
\hline Fruits & 6 & 6.6 & 7 & 7.2 & 13 & 6.9 & 0.866 \\
\hline Meat & 27 & 29.7 & 9 & 9.3 & 36 & 19.1 & $0.000 * * *$ \\
\hline Grain or cereal & 57 & 62.6 & 78 & 80.4 & 135 & 71.8 & $0.011 *$ \\
\hline Vegetables & 11 & 12.1 & 15 & 15.5 & 26 & 13.8 & 0.488 \\
\hline
\end{tabular}

$* p$ value $<0.05$

$* * * p$ value $<0.001$

consuming vegetables at least once per day $\left(\chi^{2}=9.891\right.$, $p<0.05$ ). For example, knowledge of the fact that breakfast is the most important meal of the day was not correlated with respondents' behaviour of eating breakfast every day $\left(\chi^{2}=0.708, p=0.4>0.05\right)$. In addition, students who knew that dietary products are rich in calcium and/or the main function of dietary products were not necessary the ones who were drinking at least one glass of milk (or soy milk or yogurt) every day $\left(\chi^{2}=0.096, p=0.757>0.05\right.$ and $\chi^{2}=1.566, p=0.211>0.05$, respectively). This is almost the same picture of knowledge awareness and eating behaviours as that for vegetables and fruits. The awareness that vegetables and fruits are rich in vitamin $\mathrm{C}$ was not related to the behaviour of consuming fruits at least one time per day $\left(\chi^{2}=0.074, p=0.786>0.05\right)$.

\section{Discussion}

The results of our survey indicate the absence of a clear link between nutrition knowledge awareness and healthy eating behaviours. We also found that students who knew breakfast is the most important meal of the day were not necessarily those who ate breakfast every day, and students who were aware that dietary products are rich in calcium and that the main function of dietary products is to build strong teeth and bones were not necessarily those drinking at least one glass of milk (or soy milk or yogurt) every day. These results are consistent with those of other studies [36, 37]. For example, Freeman and Bunting [38] found that all of their study participants were knowledgeable about healthy and unhealthy foods and drinks, but they were seemingly unable to apply this knowledge to modify their daily dietary choices. Bullen and Benton [39] concluded that while participants may gain factual knowledge, they do not develop the skills to bring about behavioural change. Despite this, the importance of popularizing nutrition knowledge is essential, and it is widely acknowledged that gaining accurate relevant knowledge is the basis for behavioural changes [40-42]. Our study found, for example, that an awareness that vegetables and fruits are richer in vitamin $\mathrm{C}$ was strongly related to the 
Table 4 Respondents' attitudes towards nutrition by gender

\begin{tabular}{|c|c|c|c|c|c|c|c|}
\hline \multirow[t]{2}{*}{ Questions } & \multicolumn{2}{|c|}{ Male $(n=91)$} & \multicolumn{2}{|c|}{ Female $(n=97)$} & \multicolumn{2}{|c|}{ Total $(n=188)$} & \multirow[t]{2}{*}{$p$} \\
\hline & $N$ & $\%$ & $N$ & $\%$ & $N$ & $\%$ & \\
\hline \multicolumn{8}{|l|}{ In your opinion, is nutrition important to your health? } \\
\hline Very important & 75 & 82.4 & 79 & 81.4 & 154 & 81.9 & 0.181 \\
\hline Important & 9 & 9.9 & 16 & 16.5 & 25 & 13.3 & \\
\hline Not sure & 5 & 5.5 & 1 & 1.0 & 6 & 3.2 & \\
\hline Not important & 2 & 2.2 & 1 & 1.0 & 3 & 1.6 & \\
\hline \multicolumn{8}{|l|}{$\begin{array}{l}\text { Which aspect do you think to be the most important } \\
\text { aspect when you are buying foods? }\end{array}$} \\
\hline The brand is famous & 8 & 8.8 & 9 & 9.3 & 17 & 9.0 & 0.572 \\
\hline The quality is good & 44 & 48.4 & 55 & 56.7 & 99 & 52.7 & \\
\hline The nutrition is balanced & 35 & 38.5 & 31 & 32.0 & 66 & 35.1 & \\
\hline The package is exquisite & 4 & 4.4 & 2 & 2.1 & 6 & 3.2 & \\
\hline \multicolumn{8}{|l|}{ Which aspect do you want to know most? } \\
\hline Food safety & 63 & 69.2 & 54 & 55.7 & 117 & 62.2 & 0.065 \\
\hline Nutrition issue & 18 & 19.8 & 27 & 27.8 & 45 & 23.9 & \\
\hline Food taste & 7 & 7.7 & 16 & 16.5 & 23 & 12.2 & \\
\hline Food appearance & 3 & 3.3 & 0 & 0.0 & 3 & 1.6 & \\
\hline \multicolumn{8}{|l|}{ What is your attitude to expired food? } \\
\hline Do not care about the expiration date of food & 7 & 7.7 & 7 & 7.2 & 14 & 7.4 & 0.432 \\
\hline Throw away & 71 & 78.0 & 83 & 85.6 & 154 & 81.9 & \\
\hline $\begin{array}{l}\text { Continue to eat if it only expiration date has been surpassed } \\
\text { by only } 1 \text { or } 2 \text { days }\end{array}$ & 12 & 13.2 & 6 & 6.2 & 18 & 9.6 & \\
\hline Continue to eat if there is no obvious qualitative change & 1 & 1.1 & 1 & 1.0 & 2 & 1.1 & \\
\hline \multicolumn{8}{|l|}{ Do you think it is important to develop healthy dietary habits? } \\
\hline Very important & 67 & 73.6 & 76 & 78.4 & 143 & 76.1 & 0.764 \\
\hline Important & 19 & 20.9 & 15 & 15.5 & 34 & 18.1 & \\
\hline Not sure & 4 & 4.4 & 4 & 4.1 & 8 & 4.3 & \\
\hline Not important & 1 & 1.1 & 2 & 2.0 & 3 & 1.6 & \\
\hline
\end{tabular}

behaviour of consuming vegetables at least once per day. Therefore, although nutrition knowledge awareness is not always correlated to the a specific related eating behaviour due to the complex nature of eating behaviours, we must persist in popularizing target populations' nutrition knowledge awareness. It has been recommended that single behaviours should be targeted using a comprehensive and multifaceted knowledge approach, with evidence suggesting that adolescents and their families are less likely to incorporate numerous lifestyle changes all at once and that more targeted and simple messages may be more effective in eliciting changes in eating behaviours [43, 44].

In terms of the kind of breakfast eaten, the most common food was grain or cereal-based food. This result reflects Chinese eating habits, as it has always been the Chinese tradition to have grains as the main staple food [45]. Research indicates that there has been quite marked increases in egg consumption and milk intake by the Chinese general population [46], and in our study, animal products, including eggs and dairy products, such as milk, yogurt, soy milk and bean curd jelly, ranked second in popularity. Relatively fewer respondents ate meat, vegetables and fruit for breakfast, especially fruit. China has been a leader in the substantial increase in meat consumption worldwide, with a dramatic ninefold increase in total meat consumption [47, 48]. However, our data indicate that meat eating is not a breakfast phenomenon and that it is more likely that Chinese people eat more meat during lunch and dinner.

We found that the majority of respondents wanted to know more about food safety and considered that good quality was most important when buying foods. This result clearly reflects recent opinion polls which ranked food safety among the top concerns of Chinese consumers [49]. In fact, when Chinese people become more affluent, they become more aware of - and more concerned with-the quality of consumer products, especially the quality of food products. With the relatively recent 'openness' of Chinese 
society, the media are increasingly reporting more news about food safety, and people appear to be paying more attention to this issue [50]. To many Chinese, food is not only the first necessity, but also represents their proud culture and long history. However, the substantial number of high profile food safety scandals in the past few years has seriously decreased public confidence in the domestic food industry. Various reports have blamed weak and fragmented regulatory controls, poor agricultural and veterinary practices, small-scale-and thus difficult to control-production of food and agricultural products, adulteration in food production processes, widespread corruption and unregulated pursuit of profits. One example of such a report is the Greenpeace report on excessive levels of poisonous pesticides in certain vegetables (April 2006), and various incidents on food quality include the discovery by Wuhan inspectors that blood pudding sold in Chinese markets was composed mainly of corn starch, formaldehyde, industrial grade salt and food colouring (2009), findings by Chinese officials of the illegal use of drugs in fish farming (December 2006) and the outbreak of melamine-adulterated milk and powered infant formula (2008) that affected about 300,000 babies and resulted in at least six infant deaths [51,52].

Our data indicate the emerging consumer awareness of food safety issues among young people serve as a reminder to Chinese authorities trying to deal with food safety issues [53]. In this regard, while the regulatory regime has been tightened in the short run and the legal regime strengthened over the longer term [54] there are still concerns among consumers.

To conclude, although nutrition knowledge awareness is not always correlated to the related eating behaviour(s), we should still persist in popularizing target populations' nutrition knowledge awareness and use a comprehensive and multifaceted knowledge approach to form and maintain single behaviours. In addition, we found that adolescents in rural areas of China ate relatively less healthy foods for breakfast, with very few of our respondents eating fruit, vegetables, meat, milk and eggs for breakfast; thus we should try to promote adolescents in choosing more diverse breakfast foods. Last, due to the outbreak of a substantial number of high profile food safety scandals, adolescents are becoming more aware of and concerned with food safety and the quality of food products. It is therefore important that food safety be guaranteed and food quality continuously improved in rural areas of China.

Acknowledgements This project is supported by Grant for Higher Research Degree students in School of Public Health, Griffith University.

Conflict of interest None.

\section{References}

1. World Health Organization. Healthy nutrition: an essential element of a health-promoting school. Geneva: World Health Organization; 1998.

2. World Health Organization. Towards health-promoting schools. New Delhi: WHO Country Office for India; 2008.

3. Nicklas TA, Hayes D. Position of the American Dietetic Association: nutrition guidance for healthy children ages 2 to 11 years. J Am Diet Assoc 2008;108:1038-47.

4. Vereecken C, Huybrechts I, Van HH, Martens V, Wittebroodt I, Maes L. Results from a dietary intervention study in preschools "Beastly healthy at school". Int J Public Health. 2009;54:142-9.

5. Joy-Telu HE, Malcolm T. Teaching/learning methods and students' classification of food items. Health Educ. 2011;111:66-85.

6. Inchley J, Todd J, Bryce C, Currie C. Dietary trends among Scottish schoolchildren in the 1990s. J Hum Nutr Diet. 2001;14:207-16.

7. Pérez-Rodrigo C, Aranceta J. School-based nutrition education: lessons learned and new perspectives. Public Health Nutr. 2001;4:131-9.

8. Katrin K. Evaluation of a computer-based nutrition education tool. Public Health Nutr. 2004;7:271-7.

9. Türkan. Adolescent nutrition. Turk Pediatri Arşivi. 2011;46:49-53.

10. Wahl R. Nutrition in the adolescent. Pediatr Ann. 1999;28:107-11.

11. MacLellan D, Taylor J, Freeze C. Developing school nutrition policies: enabling and barrier factors. Can J Diet Pract Res. 2010;70:166.

12. Naidoo R, Coopoo Y, Lambert EV. Impact of a primary schoolbased nutrition and physical activity intervention on learners in KwaZulu-Natal, South Africa: a pilot study. S Afr J Sports Med. 2009;21:7.

13. Lytle LA, Seifert S, Greenstein J. How do children's eating patterns and food choices change over time? Results from a cohort study. Am J Health Promot. 2000;14:222-8.

14. Davison KK, Birch LL. Childhood overweight: a contextual model and recommendations for future research. Obes Rev. 2001;2:159-71.

15. Story M, Neumark-Sztainer D, Ireland MET. Adolescent health and nutrition. J Am Diet Assoc. 2000;100:362-4.

16. Weichselbaum E, Buttriss J. Nutrition, health and schoolchildren. Nutr Bull. 2011;36:295-355.

17. McKenna M. Issues in implementing: school nutrition policies. Can J Diet Pract Res. 2003;64:208-13.

18. Tudor-Locke C, Ainsworth BE, Adair LS. Physical activity and inactivity in Chinese school-aged youth: the China health and nutrition survey. Int J Obes. 2003;27:1093-9.

19. Ye GJ. Results of previous surveys on nutritional deficiencies and overnutrition in school children in China. Presentation at training workshop. Hangzhou; 2000.

20. Fu QL, Lin KB, Ou XJ. Current nutrition status in students of Haikou city. Chin J School Health. 2001;22:314-5.

21. Chen XC. Research progress of children's nutrition in China. Chin J Prev Med. 1999;33:134-6.

22. Yang Q, Fan XQ, Wang HZ. Nutritional status in students of primary and secondary schools in Hangzhou. Chin J School Health. 2000;21:168-9.

23. http://news.xinhuanet.com/society/2011-03/29/c_121245471.htm. Accessed 29 Mar 2011.

24. Wen AH, Li AY, Chen WF, Zeng GQ, Zhang PL. The investigation of the demands of health education among children in rural areas. Chin J Health Stat. 2005;6:422-3.

25. Shi WH, Shi P, Ma LY, Ren FX. Effect evaluation of health education in primary school. Chin J Health Educ. 2006;10:744-6. 
26. Wang YF, Bentley ME, Zhai FY, Popkin BM. Tracking of dietary intake patterns of Chinese from childhood to adolescence over a six-year follow-up period. J Nutr. 2002;132:430.

27. Popkin BM. Urbanization, lifestyle changes and the nutrition transition. World Dev. 1999;27:1905-16.

28. Keyou G. The transition of Chinese dietary guidelines and the food guide pagoda. Asia Pac J Clin Nutr. 2011;20:439-46.

29. Popkin BM. The shift in stages of the nutrition transition in the developing world differs from past experiences. Public Health Nutr. 2002;5:205-14.

30. Huanan L, William AK, Jill EH. A review of Chinese food safety strategies implemented after several food safety incidents involving export of Chinese aquatic products. $\mathrm{Br}$ Food $\mathrm{J}$. 2012;114:372-86.

31. Alcorn T, Ouyang Y. World report. Lancet. 2012;379:789-90.

32. Ren F. The law priority doctrine and China's food safety legislation. Can Soc Sci. 2011;7:15-7.

33. Edward ON, Justin JK. United States import safety, environmental health, and food safety regulation in China. J Environ Health. 2012;74:28-33.

34. Oldewage-Theron WH, Egal AA. Nutrition knowledge and nutritional status of primary school children in QwaQwa. S Afr J Clin Nutr. 2010;23:149-54.

35. Turconi G, Celsa M, Rezzani C, Biino G, Sartirana MA, Roggi C. Reliability of a dietary questionnaire on food habits, eating behavior and nutritional knowledge of adolescents. Eur J Clin Nutr. 2003;57:753-63.

36. Doak CM, Visscher TL, Renders CM. The prevention of overweight and obesity in children and adolescents: a review of interventions and programmes. Obes Rev. 2006;7:111-36.

37. Lynagh M, Schofield MJ, Sanson-Fisher RW. School health promotion programs over the past decade: a review of the smoking, alcohol and solar protection literature. Health Promot Int. 1997;12:43-60.

38. Freeman R, Bunting G. A child-to-child approach to promoting healthier snacking in primary school children: a randomised trial in Northern Ireland. Health Educ. 2003;103:17-27.

39. Bullen K, Benton D. A pilot study to explore the challenges of changing children's food and health concepts. Health Educ J. 2004;63:50-60.

40. Vijayapushpam T, Antony GM, Subba Rao GM. Nutrition and health education intervention for student volunteers: topic-wise assessment of impact using a non-parametric test. Public Health Nutr. 2009;13:131-6.

41. Hamilton-Ekeke JT, Thomas M. Teaching/learning methods and students' classification of food items. Health Educ. 2011;111: $66-85$.

42. Morgan PJ, Warren JM, Lubans DR. The impact of nutrition education with and without a school garden on knowledge, vegetable intake and preferences and quality of school life among primary-school students. Public Health Nutr. 2010;13:1931-40.

43. Booth ML, Samdal O. Health-promoting schools in Australia: models and measurement. Aust $\mathrm{N}$ Z J Public Health. 1997;21:365-70.

44. Parsons C, Stears D, Thomas C. The health promoting school in Europe: conceptualizing and evaluation the change. Health Educ J. 1996;55:311-21.

45. Alexandratos $N$ (ed). World agriculture: towards 2030/50, interim report. An FAO perspective. London/Rome: Earthscan/FAO; 2006.

46. Haifei Y, Dingwei W. Research on food-chain algorithm and its parameters. Front Electr Electron Eng China. 2008;3:394-8.

47. Jiang B, Davis J. Household food demand in rural China. Appl Econ. 2007;39:373-80.

48. John K. Food consumption trends and drivers. Philos Trans R Soc B. 2010;65:2793-807.

49. Zhigang W, Yanna M, Fred G. Chinese consumer demand for food safety attributes in milk products. Food Policy. 2008;33: 27-36.

50. Chen M, He G. Chinese food safety: a case study of pig-raising industry. Manag Sci Eng. 2012;6:107-10.

51. Tamas N, Andrea P, Declan PN. Network analytical tool for monitoring global food safety highlights China. Netw Tool Food Saf. 2009;4:1-7.

52. Pei X, Tandon A, Alldrick A, Giorgi L, Huang W, Yang R. The China melamine milk scandal and its implications for food safety regulation. Food Policy. 2011;36:412-20.

53. Jacxsens L, Uyttendaele M, Devlieghere F, Rovira J, Gomez SO, Luning PA. Food safety performance indicators to benchmark food safety output of food safety management systems. Int J Food Microbiol. 2010;141:180-7.

54. Ni HG, Zeng H. Law enforcement is key to China's food safety. Environ Pollut. 2009;157:1990-2. 